\title{
DIVERSIFICACIÓN DEL GRUPO HUMECTUS DEL GÉNERO CANTHON (COLEOPTERA: SCARABAEIDAE: SCARABAEINAE) EN EL OCCIDENTE DE MÉXICO
}

\author{
GONZALO HALFFTER, ${ }^{1}$ LUIS EUGENIO RIVERA CERVANTES ${ }^{2}$ Y VIOLETA HALFFTER ${ }^{1, *}$
}

\author{
${ }^{1}$ Instituto de Ecología, A.C., Carretera Antigua a Coatepec No. 351, El Haya, 91070, Xalapa, México. \\ ${ }^{2}$ Instituto Manantlán de Ecología y Conservación de la Biodiversidad, Centro Universitario de la Costa Sur, \\ Universidad de Guadalajara, Av. Independencia Nacional 151, C.P. 48900, Autlán, Jalisco, México. <gonzalo. \\ halffter@inecol.mx>
}

Recibido: 30/07/2014; aceptado: 20/02/2015

Halffter, G., Rivera Cervantes, L. E. \& Halffter, V. 2015. Diversificación del grupo humectus del género Canthon (Coleoptera: Scarabaeidae: Scarabaeinae) en el Occidente de México. Acta Zoológica Mexicana (n. s.), 31(2): 208-220.

RESUMEN. Como una continuación de los trabajos sobre Canthon humectus (Say) (véase Introducción), en este artículo se plantea el estudio taxonómico y biogeográfico de los taxa del grupo humectus del Occidente de México, concretamente de las Sierras del Estado de Jalisco. En esta región de accidentada orografía en la que convergen la Sierra Madre Occidental, el Sistema Volcánico Transversal y la Sierra Madre del Sur, se encuentran cuatro taxa de lo que aquí consideramos como grupo humectus. Para establecer esta nueva situación taxonómica y los taxa que comprende, presentamos una descripción del grupo humectus y una clave taxonómica para todas las especies y subespecies que comprende. Se incluye además la diagnosis de los taxa que se encuentran en las sierras y costa de Jalisco: Canthon humectus humectus (Say), C.h. assimilis Robinson, C. riverai Halffter y Halffter nov. st. y C. occidentalis Halffter y Rivera sp. nov. La coexistencia de parejas de estos taxa en varias localidades, sin ejemplares de transición, plantea la necesidad de tratar a algunos de ellos como especies distintas de $C$. humectus, pero dentro del mismo grupo humectus. La comparación del grado de hibridación entre taxa que se encuentra en las sierras de Jalisco con el ya estudiado en el oriente de México, se considera un resultado de dos tiempos históricos en los procesos de dispersión-especiación del grupo humectus. Esta es una hipótesis cuya confirmación o rechazo dependerá del estudio molecular del ADN de los taxa de Jalisco, en comparación con los del oriente de México.

Palabras clave: Canthon humectus, Scarabaeinae, procesos de especiación, Jalisco.

\section{INTRODUCCIÓN}

En Jalisco, estado que se extiende desde el Altiplano mexicano hasta la costa del Pacífico, confluyen tres de los grandes sistemas montañosos mexicanos: la Sierra Madre Occidental, el Sistema Volcánico Transversal y la Sierra Madre del Sur, un complejo fenómeno geológico que muy probablemente inició su formación durante el Cretácico, pero cuyo desarrollo se intensificó en el Oligoceno (hace 26 millones de años) con la subducción de la Placa de Cocos a lo largo de la trinchera de Acapulco (Demant y Robin 1975). Esta situación orográfica forma un complejo sistema de sierras locales y valles. El único
Halffter, G., Rivera Cervantes, L. E. \& Halffter, V. 2015. Diversification of the humectus group of the genus Canthon (Coleoptera: Scarabaeidae: Scarabaeinae) in western Mexico. Acta Zoológica Mexicana (n. s.), 31(2): 208-220.

ABSTRACT. As a continuation of the work on Canthon humectus (Say) (see Introduction), in this article we carry out a taxonomic and biogeographic study of the taxa of the humectus group of western Mexico, specifically, the mountain ranges of the state of Jalisco. In this region of rugged terrain, the Western Sierra Madre Occidental Mountain Range, the Trans-Mexican Volcanic Belt, and the Southern Sierra Madre Mountain Range converge, and there are four taxa belonging to what we here consider the humectus group. As the basis for this new taxonomic situation and the taxa that comprise it, we present a description of the humectus group and a key for all of the species and subspecies in it. Also included is the description or diagnostics of the taxa found in the mountains and on the coast of Jalisco: Canthon humectus humectus (Say), C.h. assimilis Robinson, C. riverai Halffter and Halffter st. nov. y C. occidentalis Halffter and Rivera sp. nov. The coexistence of pairs of these taxa in several localities, with no transition specimens, highlights the need to treat some of them as species separate from $C$. humectus, but still within the humectus group. The comparison of the degree of hybridization among taxa that occurs in the mountains of Jalisco with that which has already been studied in eastern Mexico, is thought to be the result of two historical periods of dispersal-speciation in the humectus group. This is a hypothesis, the acceptance or rejection of which will depend on comparative molecular DNA studies of the Jalisco taxa with that of eastern Mexico.

Key words: Canthon humectus, Scarabaeinae, speciation processes, Jalisco.

declive, más o menos gradual, está en el sur del estado entre el Altiplano mexicano y los valles y sierras próximos a la costa del Pacífico. Esta compleja orografía ha influido en los procesos de especiación alopátrica, tanto en elementos de afinidades neotropicales, como en los de origen neártico, estos últimos se han dispersado de norte a sur a lo largo de las principales sierras mexicanas.

El grupo humectus pertenece al género (Canthon) de claras afinidades neotropicales (véase Halffter \& Martínez 1977). Se distribuye en todo el Altiplano mexicano hasta Arizona y Texas, extendiéndose también a las depresiones de clima tropical del Balsas y de Cuicatlán-Tehuacán al sur del Sistema Volcánico Transversal, y a los 
valles de mediana y gran altitud de Oaxaca y Chiapas, incluso hasta Guatemala. En toda esta extensión, en la que el grupo humectus se encuentra representado por poblaciones abundantes y ecológicamente importantes, se distingue un total de cuatro especies, una de ellas (C. $h$. humectus (Say)) con seis subespecies. Según el arreglo taxonómico que se plantea en este trabajo, estos nueve taxa quedan como sigue: $C$. blumei Halffter y Halffter st. nov., C. riverai Halffter \& Halffter st. nov., C. occidentalis sp. nov. y C. humectus (Say) con seis subespecies que se agrupan en tres líneas. La línea central (geográfica y filogenéticamente) integrada por $C$. humectus humectus (Say), C. h. sayi Robinson y C. h. incisus Robinson. C. h. assimilis Robinson como la subespecie más aislada en Occidente; y la línea del centro y noreste formada por $C$. h. hidalgoensis Bates y C. h. alvarengai Halffter.

Halffter (1961), Halffter y Halffter (2003) y Halffter et al. (2008) (véanse también trabajos biogeográficos incluidos en la bibliografía de $C$. humectus), han planteado que $C$. humectus y especies afines son una línea de Canthon de origen neotropical muy antiguo, que se establece en lo que es hoy el Altiplano Mexicano posiblemente en el Mioceno, antes de la elevación del Sistema Volcánico Transversal (véase Kolhmann \& Halffter 1990). Sus úni- cas afinidades estarían con los Canthon del grupo pilularius, también de origen neotropical muy antiguo y que se extiende en los Estados Unidos, diversificándose en las planicies y en el este de ese país.

Únicamente en un área relativamente reducida en el estado de Jalisco, se encuentran cuatro de los taxa, cuyas áreas de distribución se sobreponen en algunos sitios (ver Fig. 1), pero que sin embargo no presentan individuos de transición. Esta intensa especiación local es un fenómeno único en el grupo humectus y totalmente excepcional en la distribución geográfica de los Scarabaeinae. No conocemos ningún otro caso de coexistencia en un espacio limitado de cuatro subespecies o especies próximas de Canthonini. Lo anterior contrasta con lo que ocurre en el oriente de México, donde las subespecies de C. humectus están separadas por los rangos altitudinales de sus áreas de distribución, pero donde se presentan gradientes morfológicos amplios entre algunos pares de subespecies (Halffter et al. 2011, Verdú et al. 2007).

En este trabajo damos una amplia descripción de $C$. humectus, como punto de referencia para la diagnosis de las especies y subespecies del grupo en Jalisco, así como una clave taxonómica que incluye las nueve especies y subespecies. Las descripciones de especies y subespecies

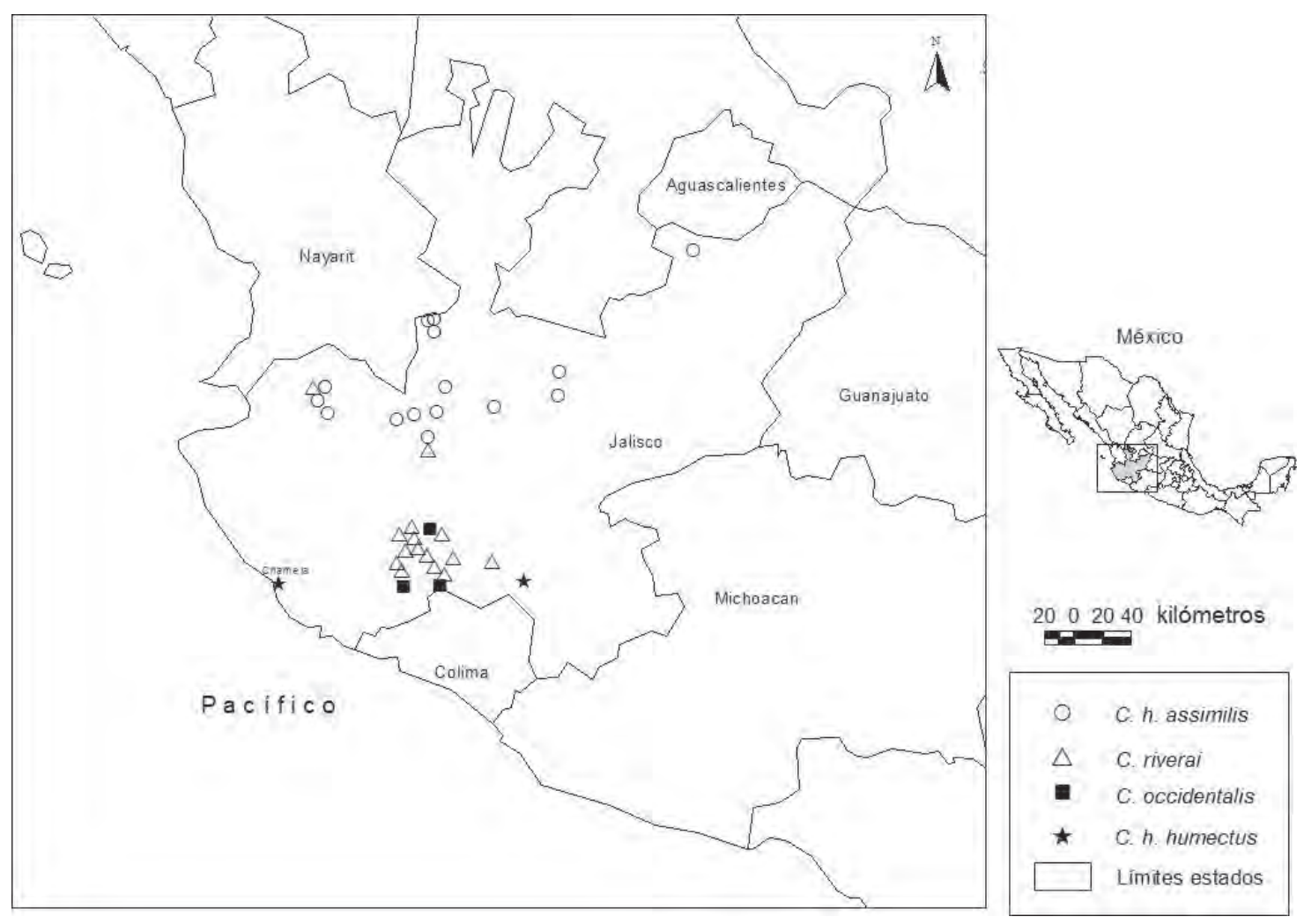

Figura 1. Mapa del Occidente de México mostrando la distribución de los Canthon del grupo humectus. Sólo se han representado las capturas correspondientes a las sierras y costa de Jalisco. Elaboración del mapa Matthías Rös. 
que existen en Jalisco se han planteado como diagnosis, por lo que se insiste en los caracteres que permiten la identificación de la especie o subespecie y se omiten aquellos otros compartidos por todos los taxa. De C. occidentalis sp. nov. se da una descripción completa. Planteamos una hipótesis sobre las relaciones entre los taxa de Jalisco y los procesos involucrados en la existencia de cuatro taxa en la región.

\section{MATERIALES}

Hemos visto material del grupo humectus, con especial énfasis en las especies de Jalisco, procedente de las siguientes colecciones: W.D. Edmonds (Marfa, Texas); G. y V. Halffter, Instituto de Ecología, A.C. (Xalapa, Veracruz); colección del Instituto de Ecología, A.C.: M.A. Morón, Instituto de Ecología, A.C.; Museum National d’Histoire Naturelle (París); José Luis Navarrete, Universidad de Guadalajara (Guadalajara, Jalisco); Luis Eugenio Rivera, Instituto Manantlán de Ecología y Conservación de la Biodiversidad, Universidad de Guadalajara (Autlán, Jalisco); Barney Streit (Tucson, Arizona).

\section{Tratamiento taxonómico}

Dentro del género Canthon (compartiendo todas las características asignadas a esta entidad supraespecífica por Halffter y Martínez 1977), el grupo humectus está muy bien definido y aislado de los otros Canthon de la Zona de Transición Mexicana y en general de las otras especies de Canthon, con la excepción ya señalada del grupo pilularius. Dentro del grupo se presenta una fuerte diferenciación geográfica que ha llevado a distinguir nueve taxa. En algunos casos, que corresponden al oriente del área de distribución, las diferencias entre las subespecies son muy pequeñas, por ejemplo entre $C$. $h$. humectus (Say) y C. h. sayi Robinson o entre C. h. hidalgoensis Bates y C. h. alvarengai Halffter (véase Halffter et al. 2011) y se presentan ejemplares de transición en los solapamientos entre las áreas de distribución. Por el contrario, los taxa de los extremos del área de distribución geográfica, como $C$. blumei Halffter \& Halffter y C. occidentalis sp. nov., se distinguen fuertemente (especialmente por la granulación de la superficie dorsal) del núcleo central integrado por C. h. humectus, C. h. sayi y C. h. incisus Robinson. En las sierras del Occidente de Jalisco (una de las áreas extremas de la distribución geográfica) dos o más especies pueden coexistir sin que se presenten individuos de transición.

Situando las especies de Jalisco dentro del esquema general del grupo humectus, éstas no corresponden a una sola línea filética diferenciada en la región. Por el contrario parecen representar distintas líneas filéticas con rela- ciones independientes con las subespecies de C. humectus del Altiplano. En otras palabras, en la región de Jalisco (periférica a lo que podemos considerar el área central del grupo humectus), no se ha presentado una, sino varias expansiones de líneas independientes del grupo (este punto es tratado en detalle en Discusión).

Incluimos en este trabajo caracteres distintivos de la genitalia masculina y femenina. A pesar de los esfuerzos exhaustivos realizados por nuestra colega Yrma López Guerrero (Instituto de Ecología, A.C.), asesorada por el Prof. Mario Zunino (Universidad de Urbino, Italia), no fue posible encontrar caracteres en la genitalia que ayudasen a la distinción de las especies y subespecies, con excepción de la forma de los parámeros del edeago, usadas desde Robinson, 1946, 1948 y Halffter, 1961. Por esta razón, los posibles caracteres de las genitalias (con la excepción antes señalada) se omiten de las claves y descripciones.

Para la identificación genérica y subgenérica de los posibles ejemplares del grupo humectus siguen siendo de utilidad las claves y diagnosis incluidas en Halffter \& Martínez (1977). Para separar C. humectus de otros Canthon (Canthon) de Norteamérica (incluido México) puede usarse la clave de Halffter (1961) y la diagnosis anexa. Para la identificación de las subespecies utilícese la clave incluida en este trabajo.

\section{Diagnosis del grupo humectus}

Forma del cuerpo oval, regularmente convexa. La coloración varía en las distintas especies, aunque predominan los tonos oscuros. La microescultura dorsal también varía en las especies.

Cabeza. Borde cefálico anterior bidentado; claramente marginado. Mejillas redondeadas. Ojos de anchura media a escasa. La estructura ventral del clípeo es un corto y pronunciado repliegue. Separación entre gula y submentón marcada por una fila de sedas ligeramente cóncava. Labio escotado en $\mathrm{V}$ con el ápice muy redondeado.

Tórax. La forma de los ángulos anteriores y posteriores del pronoto, así como la de los bordes laterales, varía ligeramente en las especies aunque corresponde al esquema general de ángulos anteriores agudos, bien marcados pero amplios; ángulos posteriores bien marcados, aunque redondeados; bordes laterales en forma de ángulo obtuso amplio y redondeado - aunque en algunos casos bien señalado- con el lado anterior ligeramente cóncavo. Ventralmente, sobre el borde externo del protórax —entre el ángulo anterior y el punto medio- se encuentra un tuberculito evidente, continuado hacia adelante por una quilla redondeada y lisa. Hypomeron con una quilla no muy notable pero perfectamente visible (en algunos in- 
dividuos, excepcionalmente puede estar muy atenuada). Parte anterior a la quilla cóncava; la concavidad está más acentuada en algunas especies.

Patas. Trocánter I con un abundante peine de sedas en su borde anterior. La microescultura de la superficie ventral de los fémures I, II y III varía en las distintas especies. Superficie dorsal del fémur I con algunas sedas largas hacia el ápice, el resto liso excepto la impresión oval y su espeso mechón de finas sedas; borde posterior y ápice del fémur I con sedas largas y rígidas. Tibia I con tres dientes bien marcados en su borde externo; las distancias relativas entre los dientes de la tibia I es un carácter para la separación de especies. Espolón apical de la tibia I distinto según el sexo. Trocánter II con un apretado grupito de largas sedas en su borde posterior. Fémur II con forma de óvalo muy alargado. En la mayor parte de las especies la superficie dorsal del fémur II tiene un grupo de cortas sedas en las cercanías de la coxa y algunas más en la región apical; además, en la región ápico-posterior algunos finos puntos de los que se desprenden seditas muy finas, apenas visibles; resto de la superficie dorsal del fémur II lisa. Tibia II con un peine de finas sedas de regular longitud en el borde dorso posterior. Fémur III muy alargado, su superficie ventral anteriormente marginada. Borde posterior del fémur III con un peine de sedas cuyo número y longitud varían según el sexo (en algunos individuos pueden haberse caído las sedas y estar sólo los puntos setígeros). Superficie dorsal del fémur III con algunos puntos muy leves y escasos. Las sedas del borde posterior de la tibia III son más largas en la mitad apical de la tibia en donde forman un peine bien definido.

Élitros. Más anchos que largos; con los bordes laterales redondeados; poco o ligeramente convexos. No se observa una verdadera impresión escutelar, pero la sutura en la región del escudete está algo deprimida. Epipleura elitral bien definida, separada del disco por una marcada quilla. La estriación elitral nunca es profunda, variando ligeramente en las distintas especies.

Pigidio. Convexidad variable según el sexo. Marginación latero-posterior evidente. La separación entre pigidio y prepigidio es un surco superficial e irregular, que tiene paralela una quilla muy fina dispuesta en el prepigidio, que suele estar más o menos borrada haciendo poco precisa la separación. La base del pigidio (el surco y su quilla paralela) forman un ángulo obtuso muy amplio, más o menos redondeado o incluso completamente redondeado.

Macho. Caracteres sexuales secundarios. Espolón de las tibias anteriores dilatado y, en mayor o menor grado, bifurcado en el ápice. Pigidio más convexo y más largo que en la hembra. Borde posterior del fémur posterior con un peine bien marcado de sedas largas y negras.

Genitalia. En la genitalia masculina los caracteres más llamativos están en los parámeros, especialmente en vista apical, con diferencias útiles en la separación de especies y subespecies (véase Fig. 2).

Hembra. Caracteres secundarios. Espolón tibial anterior aguzado hacia el ápice. Pigidio más ancho y menos convexo que en el macho. Borde posterior del fémur posterior, en la mayoría de los ejemplares, con sólo algunas sedas que no forman un peine. Excepcionalmente puede presentarse un peine bien definido.

Afinidades. El grupo humectus difiere de las especies más próximas del grupo pilularius: C. pilularius (L.) y C. imitator Brown (especies con las que algunas subespecies con granulación en pronoto y élitros podrían confundirse) por la presencia de una quilla en el hypomeron. Esta quilla puede no estar muy definida, pero siempre se presenta alguna indicación de su existencia. Además, en los taxa del grupo humectus el borde posterior del fémur metatorácico suele presentar en los machos un peine de sedas bien definido, que falta en el grupo pilularius. Por último, en vista lateral la forma de la proyección apical de los parámeros es distinta.

\section{CLAVE PARA LAS ESPECIES Y SUBESPECIES DEL GRUPO CANTHON HUMECTUS}

1.- Superficie del pronoto y élitros sin gránulos definidos. Puede ser lisa, ligeramente chagrinada o con manchitas brillantes sin relieve .................. 2 1'.- Superficie del pronoto y élitros con granulitos bien definidos ........................ 6 2.- Los tres dientes del borde externo de las tibias anteriores equidistantes, o los dos más apicales apenas aproximados en forma mínima. Coloración azul a azul-negruzco, pueden presentarse tonos morados o verdosos ........ 3 2'.- En el borde externo de las tibias anteriores, el diente distal y el medio están más próximos entre sí que los dientes medio y basal. Otra coloración ............. 4 3.- Superficie dorsal de pronoto y élitros lisa a finamente chagrinada, en algunos ejemplares con finas manchitas brillantes, apenas perceptibles en los élitros. Los dos tercios distales de la tibia anterior dilatados en forma poco marcada, gradual, sin estrechamiento en la base. Edeago según Figura 2-1. Parte este del sur del Altiplano Mexicano (hasta Michoacán y Guanajuato) y estribaciones norte del Sistema Volcánico Transversal; Altiplano de Guatemala. .............. humectus humectus (Say) 3'.- Superficie dorsal del pronoto lisa, sin ningún remanente de manchitas brillantes. Los 2/3 apicales de las tibias anteriores ensanchadas, base de la tibia adelgazada. Los dos dientes apicales de las tibias anteriores están ligeramente más próximos entre sí, que el medio y el basal. Edeago según Figura 2-2. Declive hacia el 


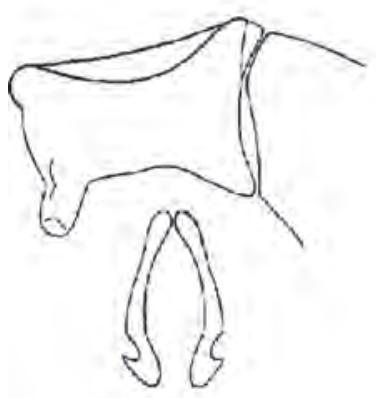

1) C.h. humectus

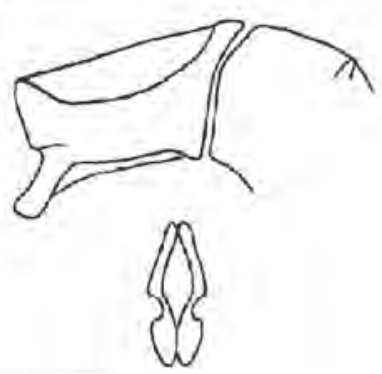

3) Ch.incisus

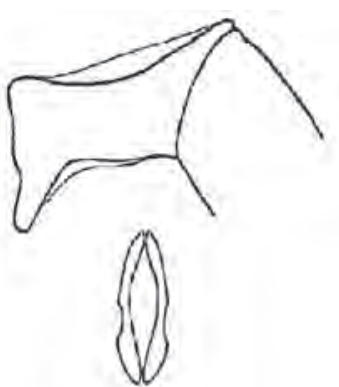

2) Ch. soyi

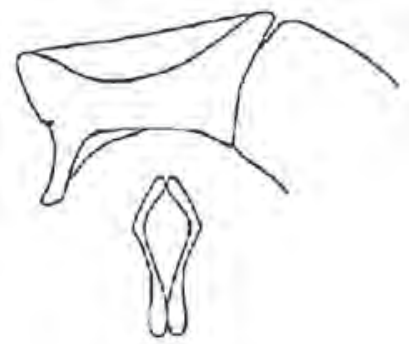

4. C.h.hidolgoensis
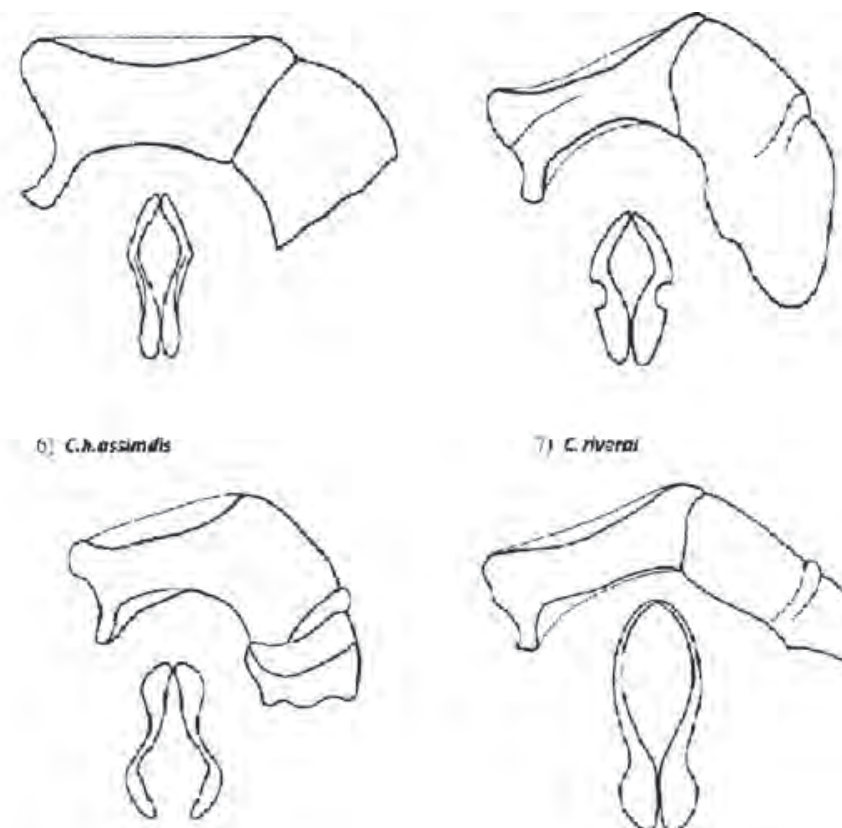

8) Coctidentalis

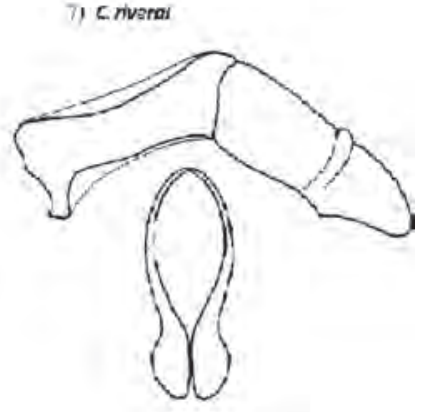

9) C. blumei

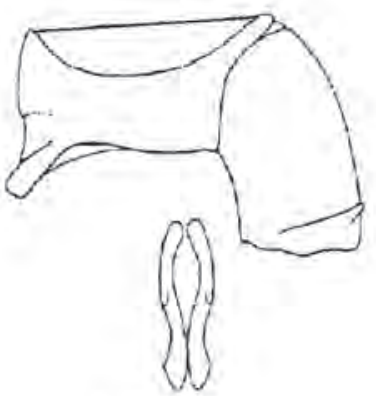

5. C.h. ahvarengei

Figura 2. Parámeros del edeago de los Canthon del grupo humectus. En la parte superior en vista lateral; en la parte inferior en vista apical. 2.1 - C. h. humectus; 2.2 - C. h. sayi; 2.3 - C. h. incisus; 2.4 - C. h. hidalgoensis; 2.5 - C. h. alvarengai; 2.6 - C. h. assimilis; 2.7 - C. riverai; 2.8 - C. occidentalis; $2.9-$ C. blumei.

Golfo de las montañas del centro de Veracruz, valles centrales de Oaxaca (y partes próximas de Puebla) y Chiapas ............... . humectus sayi Robinson 4.- Color verde obscuro. Superficie dorsal del pronoto y élitros con pequeñas áreas lisas, con muy fina puntuación sólo visible a grandes aumentos. Tibias anteriores con los dientes apical y medio más próximos entre sí que el medio y el basal. Borde interno de la tibia anterior dilatado en su mitad apical. Edeago según Figura 2-7. Longitud total 11 a $16.5 \mathrm{~mm}$. Jalisco (Sierra de Manantlán) ... C. riverai Halffter y Halffter status nov. 4'.- Color negro. Superficie dorsal de pronoto y élitros con manchitas brillantes sin ningún relieve, menos aparentes en el pronoto.................... 5 5.- Tibias anteriores con los $2 / 3$ apicales dilatados en forma progresiva. Edeago según Figura 2-3. Longitud total 12 a $16 \mathrm{~mm}$. Depresiones cálido-áridas al sur del Sistema Volcánico Transversal; valle central de Chiapas .............. humectus incisus Robinson 5'.- Tibias anteriores con los 2/3 apicales bien dilatados. Edeago según Fig. 2-6. Longitud total 13-17 mm. Jalisco y Nayarit .......... C. humectus assimilis Robinson 6.- Granulitos de la superficie dorsal con escaso relieve. . . . . . . . . . . . . . . . . . . . . . . 7 6'.- Granulitos de la superficie dorsal densos y bien definidos ........................... 8 7.- Pronoto con manchitas brillantes de escaso relieve. Edeago según Figura 2-4. Altiplano mexicano, desde Guanajuato, Querétaro e Hidalgo hasta Durango y Chihuahua por el centro de México; Ta- 
maulipas, Brownsville (Texas) y Nuevo León por el oriente . . . . . . . . . C. humectus hidalgoensis Bates 7'.- Pronoto con granulitos de escaso relieve, densos. Edeago según Figura 2-5. Nuevo León, S.L. Potosí. ............ C. humectus alvarengai Halffter 8.- Color negro. Longitud total 10 a $13 \mathrm{~mm}$. Edeago según Figura 2-9. Texas . . . . . C. blumei Halffter y Halffter status nov.

8'.- Color verde. Longitud total 14 a $16 \mathrm{~mm}$. Edeago según Figura 2-8. Jalisco ........C. occidentalis Halffter y Rivera-Cervantes sp. nov.

\section{Canthon humectus (Say)}

Remitimos a Halffter (1961) para la historia del conocimiento de $C$. humectus y la relación de sinónimos correspondiente. Se incluyen únicamente las citas posteriores a 1961 que tratan a la especie en su conjunto. Citas de las subespecies se encuentran en los incisos correspondientes.

1964. Halffter-historia biogeográfica.

1966. Halffter y Matthews-comportamiento.

1976. Halffter-distribución geográfica.

1977. Halffter y Martínez-situación taxonómica.

1985. Martínez y Valero-aparato reproductor.

1990. Kolhmann y Halffter-historia biogeográfica.

1995. Halffter et al.-distribución en Veracruz.

2003. Halffter-grupo de subespecies, distribución por estados de la República.

2003. Medina et al.-análisis filogenético Canthon.

2003. Halffter y Halffter-taxonomía de las subespecies, clave.

2007. Verdú et al.-hibridación en las subespecies del oriente.

2011. Halffter et al.-hibridación en las subespecies del oriente.

\section{Canthon humectus humectus (Say)}

Incluimos únicamente las referencias posteriores a 1961 y que corresponden claramente a la subespecie $C$. $h$. $h u$ mectus. Para un listado de las referencias anteriores véase Halffter, 1961.

1991. Kolhmann-Distribución en Distrito Federal.

1992. Arellano-Distribución en Veracruz.

1995. Halffter et al.-Distribución en Veracruz.

2000. Morón-Distribución en Puebla.

2006. Delgado y Márquez-Distribución en Hidalgo.

2008. Halffter et al.-Distribución en Hidalgo.

Diagnosis. (En las diagnosis específicas y subespecíficas se incluyen únicamente los caracteres que en algún aspecto son distintos a los señalados en la diagnosis del grupo).
La coloración varía entre azul o morado medianamente brillante a negruzco (Figura 3). Con frecuencia el pronoto suele tener más acentuada la coloración morada que los élitros; en algunos individuos se presentan tintes verdes.

Cabeza. Superficie casi lisa, con una muy fina granulación que hacia los bordes laterales y anteriores es un poco más burda; puede presentarse una puntuación muy fina y medianamente abundante.

Tórax. Pronoto casi liso, fina y levemente punteado en sus partes laterales y todavía más finamente en las cercanías de los bordes anterior y posterior; en algunos ejemplares el pronoto presenta una puntuación densa, más evidente hacia los bordes; en algunos individuos pueden presentarse muy leves manchitas brillantes entre los puntos.

Hypomeron con una quilla no muy notable, pero perfectamente visible. Metasternón con punteado disperso, muy fino y superficial, más o menos abundante en la zona media; color morado muy obscuro, casi negro.

Patas. De color morado muy obscuro, casi negro, en algunos ejemplares dorsalmente negro; en algunos ejemplares los tarsos presentan reflejos azules o verdes; reflejos de éste último color se presentan ocasionalmente en las tibias y trocánteres II y III, así como en la superficie dorsal de la tibia I.

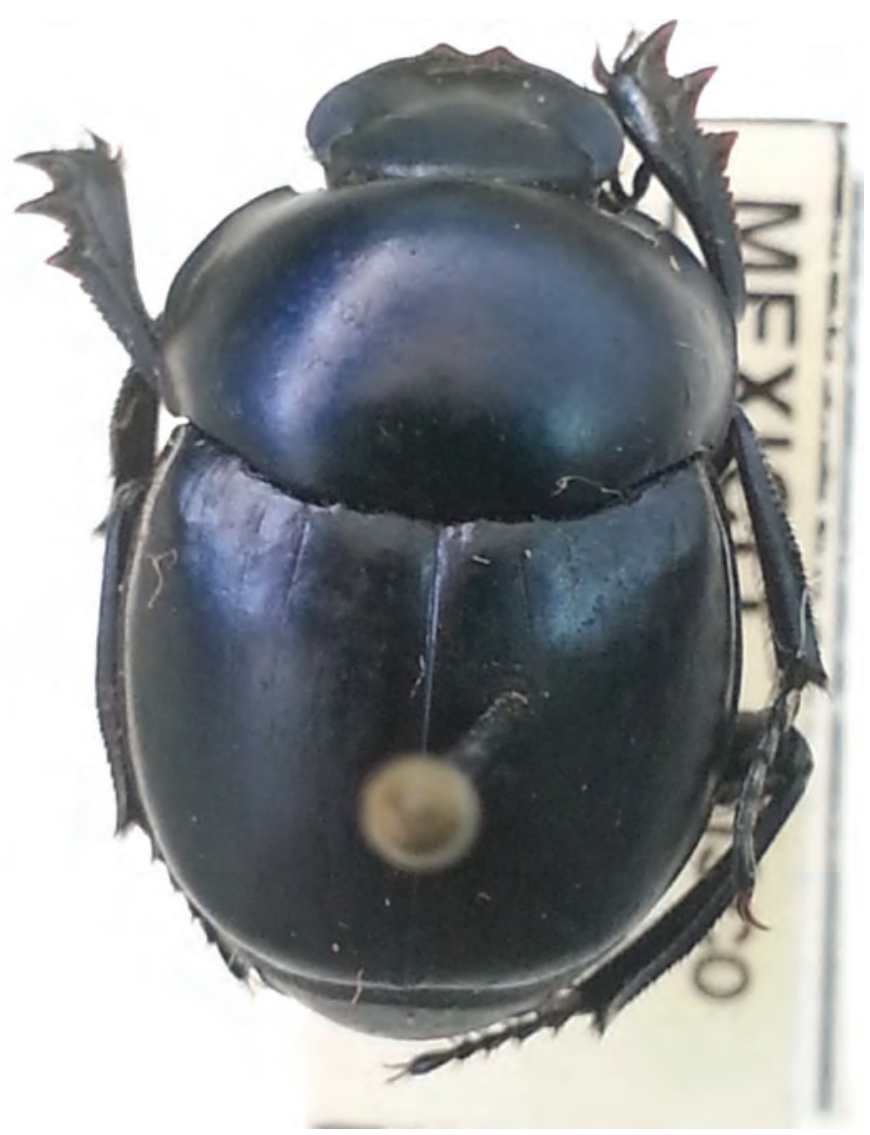

Figura 3. Canthon humectus humectus (Say) vista dorsal. 
Los tres dientes grandes del borde externo de la tibia I son equidistantes entre sí, pero los dientes I y II pueden estar ligeramente más aproximados, presentándose las dos posibilidades dentro de una misma población (Fig. 3). La tibia se va ensanchando hacia el ápice en forma muy gradual. Ápice de las tibias anteriores originalmente truncado en forma ligeramente oblicua, aunque por desgaste puede parecer recto. Borde posterior del fémur III con un peine de sedas, más notable en los machos. La superficie ventral del fémur III tiene además de puntos bien marcados, otros leves y finos, dispersos en las cercanías del borde anterior.

Élitros. Estriación apenas indicada, en algunos casos nula; en otros fina pero perfectamente visible; la profundidad de las estrías no es uniforme en toda su extensión; las estrías son de color negro, con algunos puntos leves y dispersos, a veces bien marcados. Interestrías planas. La microescultura del élitro es bastante variable, en una misma población se presentan ejemplares con los élitros lisos con puntuación muy leve y algo profusa; élitros con muy leves gránulos o con manchitas brillantes intercaladas con finos puntos, o sustituidos en el centro del élitro por éstos. Superficie tegumentaria con aspecto chagrinado muy aplanado, casi liso. Las interestrías III y V presentan un tubérculo muy pequeño en su base; la interestría II tiene un tubérculo menos marcado.

Abdomen. Prácticamente negro; alguna vez con tonos morados mucho más evidentes en el IX segmento que puede ser casi morado. Puntuación fina, más acentuada en el IX segmento.

Pigidio. Color morado o morado negruzco, medianamente brillante. Puntuación variable: en algún caso bien marcada y abundante, en otros fina y copiosa -a veces intercalada con manchitas brillantes muy pequeñas-, en otros casos prácticamente nula; se pueden presentar seditas muy cortas y doradas, en algún caso abundantes. Separación entre pigidio y prepigidio señalada por una quilla muy fina, dispuesta en ángulo obtuso redondeado o muy redondeado.

La longitud total varía en los machos entre 11 y 17 $\mathrm{mm}$, media: $14.6 \mathrm{~mm}$; en las hembras entre 10.6 y 15.25 $\mathrm{mm}$, media: $13 \mathrm{~mm}$.

Macho. Espolón de las tibias anteriores ancho, rectangular o ligeramente bifurcado en el ápice; el diente externo de la bifurcación es ligeramente más delgado y agudo. Por desgaste, a menudo el espolón se redondea, tomando forma de cuchara. Pigidio, en el centro, acortado. Edeago según Figura 2.1.

Hembra. Espolón terminado en punta aguda, dirigida hacia el exterior, a veces desgastada; arqueado en forma más o menos regular. Pigidio no acortado en el centro.

Variación. El color es algo variable dentro de C. $h$. hu- mectus. Halffter (1961) señala la variación del color dentro de una muestra de 101 ejemplares procedentes de Hueyapan (Hidalgo), en la que el 38\% correspondió a ejemplares con la superficie dorsal morada, el $28 \%$ a morado-negruzco, el $9 \%$ a negros, el $15 \%$ a verde-negruzco, el 3\% a coloraciones verdes más o menos marcadas y el 7\% a ejemplares azules. Esta gama de coloración se mantiene a través del área de distribución aunque puede haber cambios en los porcentajes.

La microescultura del pronoto, pigidio y élitros también varía, especialmente la última. La microescultura típica es lisa con una ligera puntuación. Muchos de los ejemplares que se desvían del aspecto típico son formas de transición con las dos subespecies con las que $C$. $h$. humectus entra en contacto y que presentan gránulos o manchitas brillantes (C. h. incisus y C. h. hidalgoensis).

Material examinado. Se incluye únicamente aquel material que amplía o confirma puntos dudosos de la distribución señalada por Halffter (1961). No se incluyen localidades semejantes o próximas a las señaladas por Halffter, 1961.

Michoacán: Patzcuaro, 3-VI-67, G. y V. Halffter, P. Reyes cols. 5 ejs. Paredones (Jiquilpan), 1 ej. 5.5 mi E Patzcuaro, 7200 Jt., i-VIII.1973, R.R. y M.E. Murray, 1 ej. Jalisco: 22 km NE Zapotlanejo, 30-VII-1978, Plitt y Schaffner, 1 ej. Zapotiltic, Parque Nevado de Colima, 8-XII-1996, bosque pino-encino, J. Brambila col., 1 ej. Oaxaca: 16.1 mi NW Teloloapán, 21-VII-1974, Clark Murray y Ashc Schaffner, 2 ejs. (ejemplares de transición con C. h. incisus).

Localidad típica restringida. Pastizales de los alrededores de la ciudad de México, por designación de Halffter, 1961.

Distribución geográfica. Incluimos en este trabajo la subespecie típica de $C$. humectus por el absolutamente sorprendente encuentro de tres ejemplares en La Manzanilla, municipio de la Huerta, Jalisco, localidad en la costa del Pacífico próxima a la Estación de Biología de Chamela (Universidad Nacional Autónoma de México) (Figura 1). Esta localidad, totalmente tropical, queda fuera de lo esperado por razones biogeográficas y ecológicas.

Canthon $h$. humectus es la subespecie de $C$. humectus característica del sur del Altiplano Mexicano. De oriente a occidente se encuentra en el estado de Veracruz, en las partes altas, antes del declive hacia el Golfo de México; en este declive entra en contacto y es sustituida por $C$. $h$. sayi. En los estados centrales de Puebla, Morelos, México, Distrito Federal, Hidalgo, Guanajuato y Michoacán, remonta en parte las vertientes del Sistema Volcánico Transversal hasta los $2400 \mathrm{~m}$ de altitud, en localidades como Tenancingo, Estado de México, y Tepoztlán, Estado de Morelos, en las que entra en contacto y presenta for- 
mas de transición con $C$. h. incisus, que es la subespecie que se encuentra en las tierras cálidas del sur del Sistema Volcánico Transversal.

En el extremo nororiental de su área de transición (Estado de Hidalgo) entra en contacto con C. h. hidalgoensis (subespecie del Altiplano centro y norte), pero los distintos requerimientos térmicos asociados con la termo-regulación y que responden a la altitud, impiden la hibridación (Verdú et al. 2007).

Fuera de esta distribución tan coherente y bien definida, se encuentra en los valles altos de Guatemala. También se ha citado de Chihuahua (Halffter 1961). Actualmente tenemos en estudio abundante material de los altiplanos de Chihuahua y Sonora. Aunque este material parece corresponder en su mayoría a ejemplares con caracteres de transición con $C$. $h$. hidalgoensis, no deja de ser interesante la presencia de $C$. $h$. humectus, aun en ejemplares de transición, tan al norte de su área de distribución bien definida. Este fenómeno biogeográfico se repite en otro Scarabaeinae del Altiplano Sur: Phanaeus quadridens (Say). Es posible que la interrupción de la distribución de $C$. $h$. humectus y Ph. quadridens en el Altiplano centro, hasta reaparecer en condiciones templadas en Chihuahua, sea un fenómeno reciente asociado a la aridización (PostPleistoceno) de la región centro-norte. Esta misma aridización habría favorecido la distribución de C. $h$. hidalgoensis. En este trabajo ampliamos la distribución de C. $h$. humectus (aunque de forma puntual) en el occidente del Altiplano sur a Zapotlanejo, localidad cercana a Guadalajara, Estado de Jalisco. Asimismo y además de la captura de La Manzanilla, incluimos otra colecta del estado de Jalisco, la de Zapotiltic, Parque Nevado de Colima. Todas las capturas del occidente del estado de Jalisco son de pocos ejemplares (en contraste con la presencia masiva en el Altiplano centro-sur y oriente). Lo anterior podía tener su explicación en que la subespecie se estuviera expandiendo hacia occidente en tiempos recientes o incluso actuales.

Realmente sorprendente resulta el encuentro de $C$. $h$. humectus en un pequeño punto concreto de la costa de Jalisco: La Manzanilla, en condiciones totalmente tropicales, que nada tienen que ver con la distribución en el Altiplano.

En resumen, la existencia de un área central de distribución continua y con poblaciones abundantes, y tres áreas distantes más restringidas, podía ser explicada por una antigua distribución continua a través de los Altiplanos y valles altos, desde Chihuahua hasta Guatemala, favorecida en Pleistoceno -principios del Holoceno por un clima más frio y en el norte menos árido. Los cambios en el clima: aridización y aumento de la temperatura que $C$. h. humectus soporta mal (Verdú et al. 2007), llevaron a la aparición de las actuales áreas discontinuas y a la aparición de ejemplares de transición con $C$. $h$. hidalgoensis en el Altiplano central y norte, con C. $h$. incisus en las tierras tropicales al sur del Sistema Volcánico Transversal; y con $C$. $h$. sayi en Veracruz y Oaxaca. Esta hipótesis que tiene congruencia biogeográfica y taxonómica, no explica la presencia de $C$. $h$. humectus en la costa de Jalisco. Consideramos que ésta puede ser resultado de una expansión reciente.

En toda su área de distribución $C$. h. humectus prefiere las condiciones heliófilas, aunque periféricamente puede entrar en bosques poco densos. Es una subespecie coprófaga. Su comportamiento de rodaje ha sido descrito por Halffter y Matthews (1966).

\section{Canthon humectus assimilis Robinson}

2001. Navarrete-Heredia.

2003. Halffter y Halffter-Clave.

2003. Halffter-Distribución.

Diagnosis. Coloración de la superficie dorsal negra, poco brillante.

Cabeza. Con los dientes clipeales muy poco marcados, en ángulo obtuso de ápice redondeado. Superficie finamente chagrinada.

Tórax. Superficie del pronoto con una puntuación fina y superficial, entre los puntos manchitas brillantes apenas indicadas, que pueden faltar. La microescultura está representada por un chagrinado muy fino, cuyo aspecto a veces es casi liso. Hypomeron con una quilla sólo indicada hacia el borde externo; parte anterior del hypomeron moderadamente cóncava.

Patas. De color negro, con tarsos y espolones rojizo obscuro. En la tibia anterior, los dientes del borde externo apical y medio muy aproximados, no encontrándose entre ellos-en la mayoría de los casos-ningún dientecillo pequeño, excepcionalmente puede presentarse uno; entre los dientes medio y basal se presentan uno o dos dientecillos; el diente apical con la base mucho más ancha que la de los otros dientes. El borde interno de la tibia anterior se dilata en forma acentuada desde un punto poco más basal que el medio de la tibia, siendo toda la mitad apical ancha y fuerte; ápice truncado en forma recta. Borde posterior del fémur posterior sin peine de sedas.

Élitros. Color negro. Estriación muy fina, pero clara. Microescultura del élitro formada por abundantes manchitas brillantes, más o menos claramente visibles, intercaladas con abundantes puntos finos. Superficie tegumentaria chagrinada.

Abdomen. De color negro. Con excepción del último y en menor grado penúltimo segmento abdominales, la puntuación es muy poco visible, manifiesta sólo hacia 
las porciones laterales; en estas porciones laterales se encuentran algunas cortas seditas doradas.

Pigidio. Color negro; con puntuación fina y abundante, intercalada con manchitas brillantes que se distinguen con toda claridad; superficie tegumentaria chagrinada. Base por lo general angulosa, en algunos casos arqueada. Separación entre pigidio y prepigidio apenas indicada por una quilla muy poco elevada.

Longitud total. 13 a $17 \mathrm{~mm}$; media $15.5 \mathrm{~mm}$.

Macho. Espolón de las tibias anteriores bifurcado; el diente externo es de mayor longitud y más agudo que el interno. Pigidio sólo un poco más ancho que largo. Edeago según Figura 2-6.

Hembra. Espolón agudo o espatular (por desgaste) (ver variación). Pigidio dos veces más largo que ancho.

Variación. Es una subespecie poco variable. La variación está principalmente en el grado de definición de las manchitas del pronoto y élitros. Hay una excepción con la población de la Sierra de Quila (Jalisco). En esta población se presenta variación en diferentes caracteres: hay ejemplares con la superficie dorsal brillante y otros con la superficie dorsal mate como en el resto del área de distribución; las hembras presentan el espolón de las tibias anteriores bifurcado, aunque en forma ligeramente diferente a como es en el macho, en ambos sexos uno de los dientes es más agudo que el otro.

Material examinado. Además del incluido en Halffter (1961), el siguiente: Jalisco: Ahualulco, 4/X/2003, J. Álvarez col., 1 ej.; Ajijic, VIII/1947, 5 ejs.; Ameca, entre 1225 y 1580 m alt., varias fechas y colectores, 137 ejs.; Ejutla, 950 m alt., 29/IX/1996, bosque tropical caducifolio, S. Montes col., 3 ejs.; Guachinango, 12/VIII/1994, Nogueira col., 1 ej.; Guadalajara, 2 ejs.; idem, 1200 m alt., 13/VIII/1993, L. Rivera col., 2 ejs.; Hostotipaquillo, entre 420 y $1108 \mathrm{~m}$ alt., varias fechas y colectores, 10 ejs.; Mascota, $1250 \mathrm{~m}$ alt., varias fechas y colectores, 59 ejs.; Mixtlán, Cerro Chato, Km 48 carr. Ameca-Mascota, 1710 m alt., 5/VI y 3/VII/2004, J.L. Navarrete-Heredia y V. Flores col., 4 ejs.; Ojuelos, 27/VII/2003, M.F. Núñez col., 5 ejs.; Potrero de Barrera, entre 650 y 821 m alt., varias fechas y colectores, 31 ejs.; San Sebastián del Oeste, Cerro de la Bufa, 1859 m alt., 10/VII/1997, J.L. Navarrete col., 2 ejs.; Sierra de la Primavera (Tala), 1200 m alt., M. Arias col.; Tala, Ahuisculco, 1350 m alt., 12/VI/1996, G. Quiroz col., 1 ej.; Tecolotlán (Sierra de Quila), entre 1550 y 1660 m alt., varias fechas y colectores, 48 ejs.; Zapopan, Ixcatan, $1200 \mathrm{~m}$ alt., 1/VII/1996, H. Fierros col., 1 ej.; Nayarit: La Yesca, 442 m alt., 17/IX/2004, W.E. López, J. Cortés-Aguilar y J.L. Navarrete-Heredia, 1 ej.; Cerro del Testerazo, 24/IX/1961, O. Reyes, 1 je.; Mirador Barranca de Oro, 1/VIII/2003, R.E. Halffter col., 1 ej.

Localidad típica. Compostela, Nayarit (Robinson 1946).
Distribución geográfica. Se distribuye desde el extremo occidental del Altiplano a varias de las sierras integrantes de la Sierra Madre del Sur que se encuentran entre el mismo y las costas del Pacífico (no en las costas) a la latitud de Guadalajara, Jalisco (ver Fig. 1).

Se encuentra desde terrenos descubiertos o con matorral xerófilo, hasta bosques caducifolios o subcaducifolios. Es diurno, coprófago, aunque se captura con frecuencia en trampas con carroña.

Afinidades. Es una subespecie bien definida por la dilatación tan marcada de la mitad apical de la tibia anterior; la aproximación de los dos dientes distales de la misma tibia, y las manchitas brillantes de pronoto, élitros y pigidio, además del edeago. El taxón más próximo sería $C$. h. incisus con distribución al sur del Sistema Volcánico Transversal y que pertenece al núcleo central de subespecies de $C$. humectus, el integrado por $C$. $h$. humectus, $C$. h. incisus y C. h. sayi.

\section{Canthon riverai Halffter y Halffter}

1995. Canthon humectus subespecie nueva. García-Realreferencia ecológica.

2003. Canthon humectus riverai. Halffter y Halffter-descripción.

Diagnosis. Coloración de la superficie dorsal verde, muy uniforme en todos los ejemplares examinados, en algún caso con brillos cobrizos o dorados muy ligeros. Superficie dorsal del pronoto y élitros con pequeñas manchas lisas, más o menos definidas según los ejemplares, en algún ejemplar casi inaparentes; con muy fina puntuación sólo visible a fuertes aumentos. Brillo sedoso.

Cabeza. Borde anterior del clípeo claramente bidentado, dientes en triangulo obtuso separados por una muesca en V abierta.

Tórax. Quilla del hypomeron bien definida; parte anterior a la quilla excavada.

Patas.- Tibia anterior con los dientes apical y medio más próximos que el medio y basal; borde interno de la tibia dilatado en su mitad apical.

Abdomen. Separación entre pigidio y prepigidio marcada por una quilla en forma de arco.

Longitud total.- Machos: 12.5 a 16.5 mm (media 14.6 $\mathrm{mm}$ ); hembras: 11 a $16 \mathrm{~mm}$ (media $13.5 \mathrm{~mm}$ ).

Macho. Espolón apical de la tibia anterior bifurcado, el diente externo marcadamente más agudo que el interno. En vista apical los parámeros del edeago con una escotadura bien definida (Figura 2-7).

Hembra. Espolón apical de la tibia anterior agudo. El último esternito abdominal no estrechado en la parte central.

Material examinado. Incluyendo los tipos, el siguiente 
material: Colima: carretera Colima-Minatitlán, desviación al Sauz, 1000 m alt., 10/IX/1999, J.L. Navarrete col. 1 je.; Jalisco: Autlán (Sierra de Manantlán), entre 900 y 1800 m alt., varias fechas y colectores, 41 ejs.; El Grullo, entre 820 y $1100 \mathrm{~m}$ alt., varias fechas y colectores, 4 ejs.; El Limón, 870-880 m alt., VII y X/1988, L. Rivera-Cervantes y V. Bedoys col., 25 ejs.; El Tigre, 1360 m alt., 27/VII/1988, varios colectores, 12 ejs.; Ejutla, 960-1000 m alt., 20/VIII y 4/IX/1999, V González col., 4 ejs.; Poncitlán, 1500 m alt., 11/VII/1995, G. Nogueira col., 2 ejs.; Sierra Tapalpa, La Yerbabuena, 1950 m alt., 4/VIII/1994, G. Nogueira col., 1 ej.; San Sebastián del Oeste, 821 m alt., 24/VII/2007, L. Rivera col., 1 ej.; San Gabriel, 1569 m alt., 5-9/X/1991-1994, F. A. Noguera y A. Rodríguez col., 5 ejs.; Sierra de Manantlán, entre 700 y 1000 m alt., varias fechas y colectores, 17 ejs.; Tecolotlán (Sierra de Quila), 1580 m alt., VII/2001, H. Bustos col., 7 ejs.; Tonaya, $800 \mathrm{~m}$ alt., varias fechas, R. Carrillo col., 17 ejs.; Tuxcacuesco, $1000 \mathrm{~m}$ alt., varias fechas y colectores, 45 ejs.; Union de Tula, 1110-1350 m alt., varias fechas y colectores, 14 ejs.; Zenzontla (Sierra de Manantlán), 1000 m alt., 20/VI y 19/X/1988, E. García Real col., 6 ejs.

Localidad típica. Zenzontla, Municipio Tuxcacuesco, Jalisco 1940’19” N, 10404'89”O. Halffter y Halffter, 2003. Distribución geográfica. C. riverai fue descrito de cuatro localidades de la parte baja de la Sierra de Manantlán: El Tigre (700 m alt.), Zenzontla (1000 m alt.), El Limón (870 m alt.) y El Grullo (870 m alt.). El material adicional que hemos examinado corresponde a municipios próximos a la misma Sierra de Manantlán, excepto las capturas de Poncitlán, ubicado hacia el Altiplano sur de Jalisco, próximo a la zona metropolitana de Guadalajara, San Sebastián del Oeste al noroeste de Jalisco (parte de la Sierra Madre Occidental) y Tecolotlán, localidad en la Sierra de Quila, por lo que se amplía significativamente el área de distribución que sigue siendo muy restringida al occidente del estado de Jalisco (Fig. 1). Se encuentra entre los 800 y los $1800 \mathrm{~m}$ de altitud, en bosques tropicales caducifolios y encinares caducifolios, aunque también en sitios perturbados o sin vegetación arbórea. Es coprófago y diurno, aunque de manera ocasional se le ha capturado por medio de trampas de luz entre las 20:00 y 21:00 hrs.

Afinidades. Dentro del conjunto de especies y subespecies del grupo humectus, C. riverai es semejante a $C$. $h$. incisus, incluyendo caracteres importantes como la vista apical del edeago, y la configuración de la tibia anterior y sus dientes. Lo anterior implicaría una posible comunicación en condiciones más cálidas entre la subespecie más tropical de C. humectus (sur del Sistema Volcánico Transversal) y las Sierras de Jalisco, distribución que se presenta también en otros grupos de organismos (para plantas, véase Rzedowski 1978).

\section{Canthon occidentalis Halffter y Rivera, sp. nov.}

Descripción. Superficie dorsal (Fig. 4) verde obscuro con gránulos abundantes, más brillantes que el fondo. Patas y superficie ventral negras con algún reflejo verdoso.

Cabeza. Superficie chagrinada con un denso granulado menos marcado que el del pronoto y élitros. Ojos estrechos, bordes interno y externo rodeados por una fina quilla. Borde cefálico anterior bidentado, los dientes poco marcados y separados por una escotadura en $\mathrm{V}$ muy amplia (Fig. 4). Línea supraclipeal extendiéndose mucho más allá de la base de los dientes clipeales. Mejillas redondeadas, la separación con el clípeo apenas señalada. Borde posterior de la cabeza marginado.

En vista ventral, la estructura entre los dientes está formada por un repliegue transversal que une las bases de

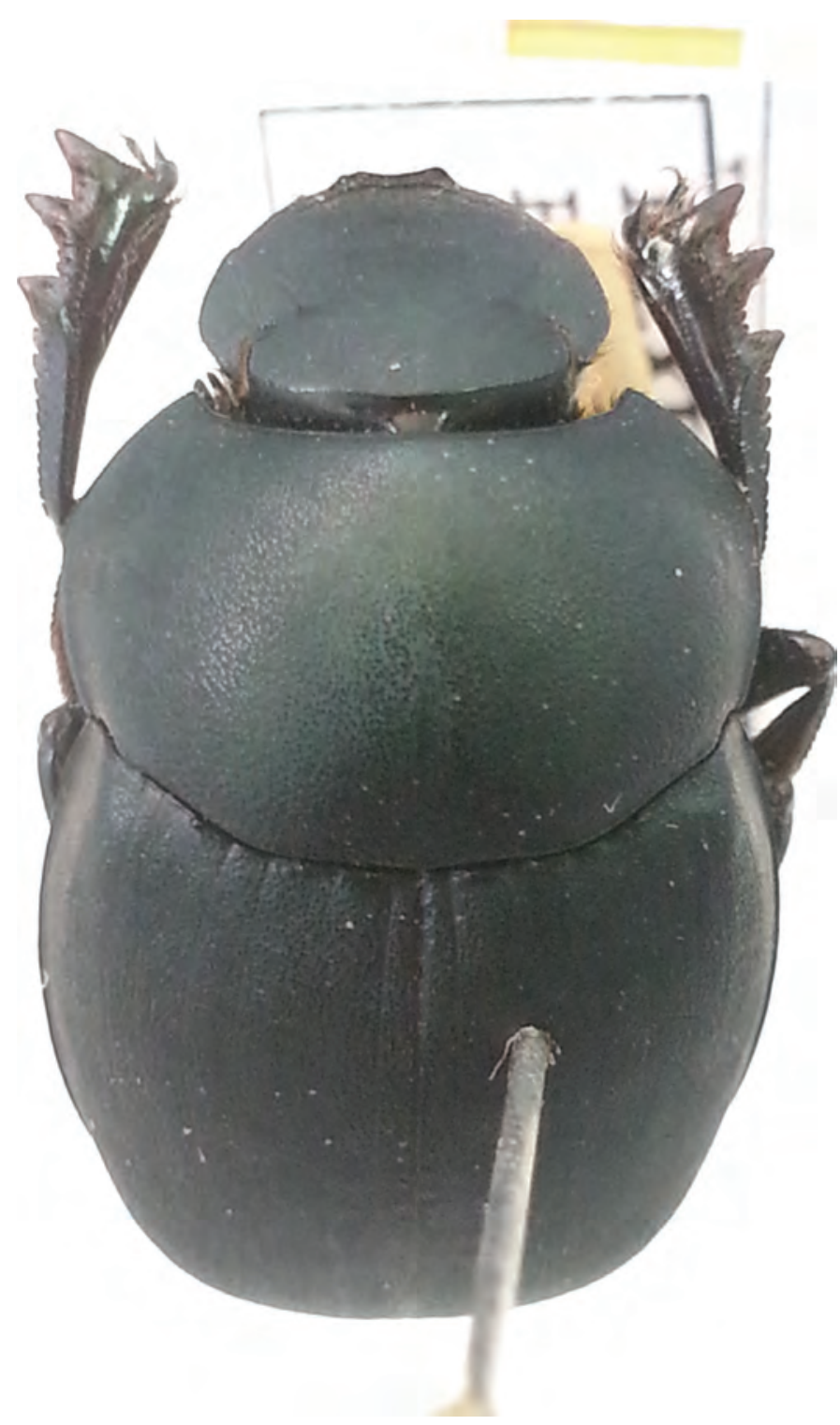

Figura 4. Canthon occidentalis sp. nov. Vista dorsal. 
los dientes clipeales. Separación entre gula y submenton curva, cóncava, muy poco profunda. Borde anterior del labio con escotadura en $\mathrm{V}$ profunda.

Tórax. Pronoto finamente chagrinado, sobre el que resalta un granulado muy denso en toda su superficie; entre el granulado, sobre la línea media, algunos puntos poco profundos, marcadamente más anchos que largos (Fig. 5). Ángulos anteriores agudos y bien definidos. Bordes laterales angulosos, aunque el ápice del ángulo está redondeado. Ángulos posteriores rectos, pero bien definidos. Borde posterior ligeramente sinuoso. Bordes anterior y laterales marginados por una fina quilla; borde posterior sin marginar.

Hypomeron con una quilla bien definida y completa. La parte del hypomeron anterior a la quilla ligeramente excavada y con algunas sedas; la parte posterior chagrinada con alguna fina sedita. Zona media del metasternón chagrinada, con puntuación más definida hacia la parte posterior.

Patas. Superficie ventral del fémur anterior finamente chagrinada; el borde anterior con un peine de sedas bien definido; el borde posterior también con un peine de sedas; algunos puntos setígeros hacia la inserción de la tibia. Tibia anterior gradualmente ensanchada hacia el ápice (Fig. 4). Ápice recto. Los dos dientes apicales del borde externo ligeramente más próximos entre sí que el medio y el basal.

Superficie ventral del fémur medio finamente chagrinada y con puntuación claramente visible. El fémur posterior semejante, pero con granulitos aplanados; en vista ventral el borde anterior del fémur III claramente marginado.

Élitros. Con ocho estrías poco profundas, pero claramente visibles. La superficie presenta un chagrinado bien definido y granulitos brillantes, menos densos que en el pronoto, pero claramente visibles (Fig. 6).

Longitud total. 14 a $16.5 \mathrm{~mm}$, media $15.5 \mathrm{~mm}$.

Macho. Último esternito abdominal estrechado en el centro. Espolón de las tibias anteriores ensanchado y bifurcado en el ápice. El borde apical del edeago con un ángulo bien marcado en su parte media (Figs. 2-8); en vista lateral con la proyección apical bien definida.

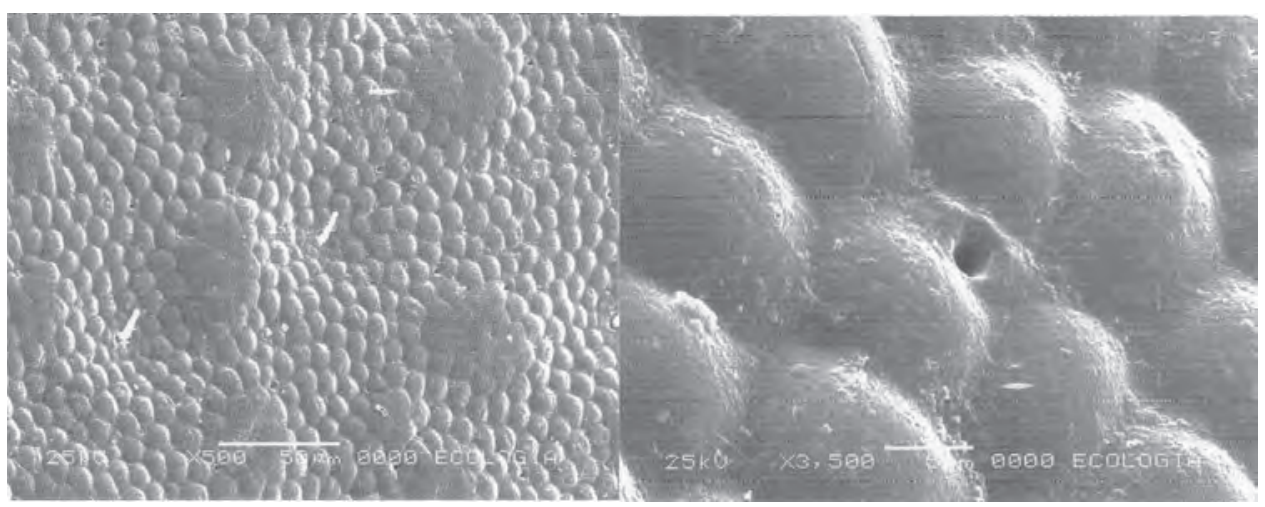

Figura 5. Microescultura del pronoto en C. occidentalis. Superior - A 500 aumentos; Inferior - A 3500 aumentos, se ve claramente un poro de glándula cuticular entre el chagrinado del pronoto. Compárese con las microfotografías equivalentes de otros taxa del grupo humectus publicadas por Halffter y Halffter, 2003.

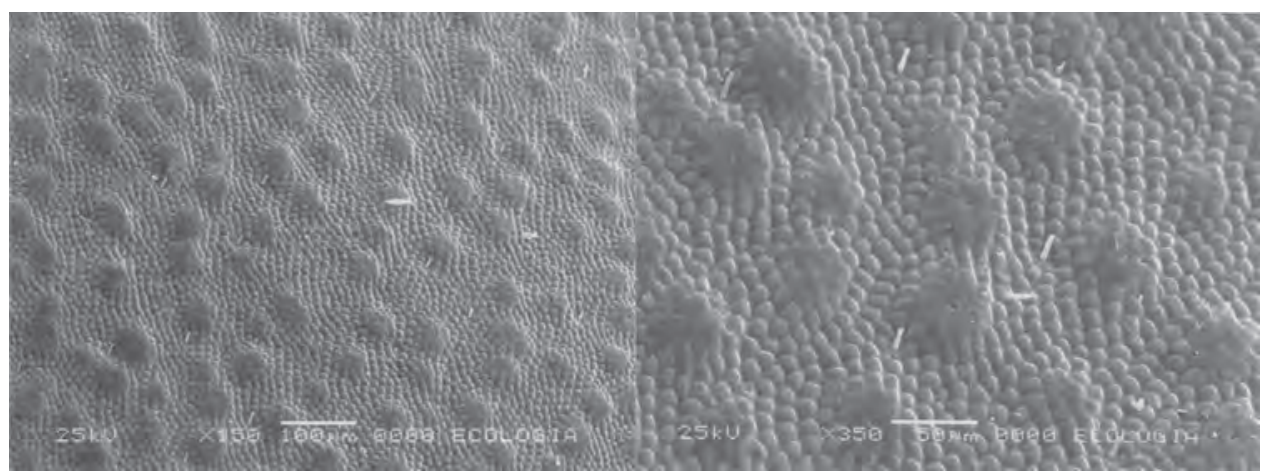

Figura 6. Microescultura de los élitros en C. occidentalis. Superior - A 150 aumentos; Inferior - A 350 aumentos. Compárese con las microfotografías equivalentes de otros taxa del grupo humectus publicadas por Halffter y Halffter, 2003. 
Hembra. Último esternito abdominal no estrechado en el medio. Espolón apical de la tibia anterior curvado y aguzado hacia el ápice.

Variación. La única variación observada está en el color que ocasionalmente puede ser más negro de lo señalado, o por el contrario totalmente verde.

Material examinado. Holotipo macho. MEXICO, Jalisco, Ejutla, 2-4-X-1999, J. García, col. Loc. La Estancia, Vegetación secundaria, Alt. 960 m, Coprotrampa.

Alotipo hembra. IDEM al macho, excepto V. Gonzalez, col.

Depósito. Colección entomológica del Instituto Manantlán de Ecología y Conservación de la Biodiversidad (IMECBIO), en la ciudad de Autlán de Navarro, Jalisco.

Paratipos con las etiqueta siguientes: Jalisco: Cuautitlán, carretera La Rosa-Chacala, $590 \mathrm{~m}$ alt., bosque tropical subcaducifolio; 10/VII/2007, L. Rivera col., 2 ejs.; ídem excepto $550 \mathrm{~m}$ al., 14/IX a 4/X/2008, 26 ejs.; ídem excepto R. Viejo, 520 m alt., 12/XI a 1/XII/2008, I Padilla col., 4 ejs.; Ejutla, 1000 m alt., distintas capturas de agosto-septiembre 1999, 119 ejs, en bosque tropical caducifolio y en lugares descubiertos; Tonaya, Las Higueras, 800 m alt., 7-13/VIII/2001, R. Carrillo col., 1 je.; Cuautitlán, El Roblón, 550 m alt., 14/IX/2008, I. Padilla col., 1 ej. Colima: carretera Colima-Minatitlán, desviación al Sauz, 1000 m alt., 10/X/1999, J.L. Navarrete col., 2 ejs. Comala, Brecha a Campo Cuatro, B. trop. Subcaducifolio, Alt. 1080 mt., en excreta de caballo, 24-VI-2011, L. Rivera, col., 27 hembras, 10 machos.

Material en las colecciones Halffter (Xalapa) e Instituto Manantlán de Ecología y Conservación de la Biodiversidad (Autlán, Jalisco).

Localidad típica. La Estancia, municipio de Ejutla, Jalisco. 1956'12” N, 10403’37” O.

Distribución geográfica. Se ha encontrado tanto en bosques tropicales caducifolios y subcaducifolios, como en terrenos descubiertos totalmente heliófilos. Acude tanto a carroña como a excremento humano o vacuno.

La distribución de $C$. occidentalis es muy particular. Se encuentra restringido a zonas limítrofes con la Sierra de Manantlán, con poblaciones reducidas en Comala y Minatitlán (Colima) (Fig. 1). Sin embargo no se ha encontrado en la Sierra de Manantlán propiamente dicha. Aparentemente está en un proceso de dispersión hacia el noroeste de Jalisco.

Afinidades. Esta especie coincide con C. blumei en presentar en la superficie dorsal del cuerpo una granulación densa y bien definida. Se separa, además de por una distancia geográfica de varios cientos de kilómetros, por el color verde, negro en $C$. blumei; la mayor longitud total 14 a $16 \mathrm{~mm}$, frente a C. blumei con 10 a $13 \mathrm{~mm}$. C. occidentalis es una especie aislada de las existentes en occidente y centro de México.

\section{DISCUSIÓN}

Al estudiar el conjunto de taxa en torno a $C$. humectus se pueden seguir dos posiciones igualmente válidas: la primera tomar el conjunto como una especie con nueve subespecies; la segunda considerar un grupo supraespecífico muy compacto con cuatro especies. En realidad ambas alternativas son muy semejantes.

Bajo cualquiera de las dos alternativas, el núcleo central de C. humectus está conformado por un conjunto de subespecies muy próximas y con numerosos casos de hibridación, son C. h. humectus, C. h. sayi y C. h. incisus. De este conjunto se separan dos ramas: una que comprende $C$. h. assimilis y C. riverai, y una segunda que comprende $C$. $h$. hidalgoensis y $C$. h. alvarengai. Entre estas ramas y el núcleo central ocurren algunas hibridaciones (no con C. riverai).

Más diferentes, fuera del conjunto antes señalado y totalmente separadas geográficamente, están C. blumei y C. occidentalis a las que damos el rango de especies. No hemos encontrado ningún caso de hibridación con algún otro taxa, pero el conjunto de caracteres prescindiendo de la granulación (que puede ser en ambas especies una sinapomorfia) es muy afín al de los otros humectus.

Sea $C$. humectus una especie con nueve subespecies, o sea un "grupo humectus" con cuatro especies: C. humectus con seis subespecies, C. riverai, C. blumei y C. occidentalis, se trata de un conjunto muy coherente, totalmente separado de los otros Canthon de México y con sólo una cierta afinidad con el grupo pilularius que tiene una distribución geográfica muy definida en los Estados Unidos, con una penetración en el norte de México.

¿Por qué se han encontrado hibridaciones en otras partes de la extensa área de $C$. humectus y eso no ocurre en occidente?

Una explicación podría ser que en Occidente (Jalisco) se encuentran tres taxa (assimilis, riverai y occidentalis) que evolucionaron desde antiguo (Cenozoico Superior) en condiciones orográficas de aislamiento. La actividad geomorfológica del conjunto de Sierras de Jalisco no ha cesado. Sólo en tiempos recientes se presentan las condiciones que permiten los contactos. La presencia de $C$. $h$. humectus en la costa (Chamela) sería un fenómeno nuevo, posiblemente actual y en proceso activo de expansión.

AGRADECIMIENTOS. Nuestra gratitud a todos los investigadores que a continuación mencionamos por habernos facilitado material de las colecciones a su cargo: W.D. Edmonds (Marfa, Texas), Barney Streit (Tucson, Arizona), Miguel Angel Morón (Instituto de Ecología, A.C.), Jose Luis Navarrete Heredia (CUCBA, Universidad de Guadalajara), Edith García Real (IMECBIO, Universidad de Guadalajara), Ricardo Ayala (Estación de Biología, Chamela, UNAM). A todos ellos nuestro agradecimiento. Leticia Guerrero Guerrero, Fernando Esco- 
bar Hernández y Tiburcio Laez Aponte, así como Matthías Rös (todos ellos del Instituto de Ecología, A.C.) nos han dado una muy valiosa ayuda con las ilustraciones.

\section{REFERENCIAS}

Arellano Gámez, L. 1992. Distribución y abundancia de Scarabaeidae y Silphidae (Insecta: Coleoptera) en un transecto altitudinal en el Estado de Veracruz. Tesis para obtener el título de Bióloga. UNAM, Facultad de Ciencias. 139 pp.

Delgado, L. \& Márquez, J. 2006. Estado del conocimiento y conservación de los coleópteros Scarabaeoidea (Insecta) del Estado de Hidalgo, México. Acta Zoológica Mexicana (n.s.), 22: 57-108.

Demant, A. \& Robin, C. 1975. Las fases del volcanismo en México; una síntesis en relación con la evolución geodinámica desde el Cretácico. Revista Instituto de Geología, UNAM, 75: 70-83.

García Real, E. 1995. Abundancia, distribución y estructura de la comunidad de escarabajos coprófagos y necrófagos (Coleptera: Scarabaeidae) en un gradiente altitudinal de la Sierra de Manantlán, Jalisco-Colima, México. Tesis de Maestría en Ciencias, Colegio de Postgraduados, Montecillo, México. 129 pp.

Halffter, G. 1961. Monografía de las especies norteamericanas del género Canthon Hoffsg. Ciencia (Méx.), 20: 225-320.

Halffter, G. 1964. La entomofauna americana: ideas acerca de su origen y distribución. Folia Entomológica Mexicana, 6: 108 pp.

Halffter, G. 1976. Distribución de los insectos en la Zona de Transicion Mexicana. Relaciones con la entomofauna de Norteamérica. Folia Entomológica Mexicana, 35: 1-63.

Halffter, G. 2003. Tribu Scarabaeini. En Moron, M.A. (Ed). Atlas de los Escarabajos de México. Coleóptera-Lamellicornia, Vol. II, pp. 31-43. Argania Editio, Barcelona.

Halffter, G., Favila, M. E. \& Arellano, L. 1995. Spatial distribution of three groups of Coleoptera along an altitudinal transect in the Mexican Transition Zone and its biogeographical implications. Elytron, 9: 151-185.

Halffter, G., Halffter, V., Martínez-Sánchez, K. M., Moreno, C. E. \& Sánchez-Rojas, G. 2011. Hybridization between subespecies of Canthon humectus (Say) (Coleoptera: Scarabaeidae). The Coleopterists Bulletin, 65: 425-431.

Halffter, G. \& Martínez, A. 1977. Monografía de los Canthonina americanos, IV (Coleoptera, Scarabaeidae). Folia Entomológica Mexicana, 38: 29-107.
Halffter, G. \& Matthews, E. G. 1966. The natural history of dung beetles of the subfamily Scarabaeinae. Folia Entomológica Mexicana, 12-14: 1-312.

Halffter, G., Verdú, J. R., Márquez, J. \& Moreno, C. E. 2008. Biogeographycal analysis of Scarabaeinae and Geotrupinae along a transect in Central Mexico (Coleoptera, Scarabaeoidea). Fragmenta Entomologica, Roma, 40: 273-322.

Halffter, V. \& Halffter, G. 2003. Nuevas subespecies de Canthon humectus (Say) (Coleoptera: Scarabaeidae: Scarabaeinae). Folia Entomológica Mexicana, 42: 329-340.

Kohlmann, B. 1991. Dung beetles in Subtropical North America, pp. 116-132. In: Hanski, I. \& Y. Cambefort (Eds). Dung Beetle Ecology. Princeton University Press.

Kohlmann, B. \& Halffter, G. 1990. Reconstruction of a specific example of insect invasion waves: the cladistics analysis of Canthon (Coleoptera: Scarabaeidae) and related genera in North America. Quaestiones Entomologicae, 26: 1-20.

Martínez M., I. \& Valero R., L. 1985. Determinación de glucógeno y lípidos en adipocitos y glándula de la espermateca durante la vitelogénesis en Copris armatus Harold y Canthon humectus Say (Coleoptera: Scarabaeidae). Folia Entomológica Mexicana, 63: 31-39.

Medina, C., Scholtz, C.H. \& Gill, B.D. 2003. Morphological variation and systematic of Canthon Hoffmansegg 1817 and related genera of new world Canthonini dung beetles (Coleoptera: Scarabaeinae). Deutsche Entomologische Zeitschrisft, 50: 23-68.

Morón, M. A., Aragón, A., Tapia, A. M. \& Rojas, R. 2000. Coleoptera Lamellicornia de la sierra del Tentzo, Puebla, México. Acta Zoológica Mexicana (n.s.), 79:77-102.

Navarrete-Heredia, J. L., Delgado, L. \& Fierros-López, H. E. 2001. Coleoptera Scarabaeoidea de Jalisco, México. Dugesiana, 8: 37-93.

Robinson, M. 1946 Studies in the Scarabaeidae III. Transactions of the American Entomological Society, 72: 49-59.

Robinson, M. 1948. A review of the species of Canthon inhabiting the United States. Transactions of the American Entomological Society, 74: 83-99.

Rzedowsky, J. 1978. Vegetación de México. Editorial Limusa, México. 432 pp.

Verdú, J. R., Arellano, L., Numa, C. \& Mico, E. 2007. Role of endothermy in niche differentiation for ball-rolling dung beetles (Coleoptera: Scarabaeoidea) along an altitudinal gradient. Ecological Entomology, 32: 1-8. 